\title{
Remodeling of a commercial plug-in battery electric vehicle to a hybrid configuration with a PEM fuel cell
}

\author{
Vicente Roda ${ }^{1,3}$, Javier Carroquino ${ }^{2,4}$, Luis Valiño ${ }^{1}$, Antonio Lozano ${ }^{1}$, Félix Barreras ${ }^{1, \dagger}$ \\ ${ }^{1}$ LIFTEC, CSIC-Univ. of Zaragoza, Maria de Luna 10, 50018 - Zaragoza (Spain) \\ ${ }^{2}$ University of Zaragoza, Dept. of Electrical Engineering, Maria de Luna 3, 50018 -Zaragoza (Spain) \\ 3 Present address: Institut de Robòtica i Informàtica Industrial, CSIC-UPC, Llorens i Artigas 4-6, \\ 08028 Barcelona (Spain) \\ ${ }^{4}$ Present address: Intergia Energía Sostenible S.L., Av. Cataluña 19, 50014 - Zaragoza (Spain)
}

\section{ABSTRACT}

In the present research, a commercial battery-powered pure electric vehicle was suitably modified to convert it into a hybrid one integrating a PEMFC stack. The hydrogen supply system to the stack included a passive recirculation system based on a Ventury-type ejector. Besides, in order to achieve an optimum operation of the PEMFC stack, a discrete state machine model was considered in its control system. The inclusion of a rehabilitation operating mode prevented the stack from possible failures, increasing its lifetime. It was verified that for the rated operating point when supplying power to the vehicle $(2.5 \mathrm{~kW})$ the hydrogen consumption decreased, and the actual efficiency (47.9\%) PEMFC was increased close to $1 \%$. Field tests performed demonstrate that the range of the hybrid electric vehicle was increased by $78 \%$ when compared to the one of the original battery electric car. Also, under the tested experimental conditions in hybrid mode, $34 \%$ of the total energy demanded by the electric machine of the vehicle was supplied by the PEMFC stack.

Keywords: Zero emission vehicles; Battery electric car; Hybrid vehicle; Hydrogen; PEM fuel cells

\footnotetext{
+ Corresponding Author: felix@litec.csic.es

Ph.: (+34) 976506 520. Fax: (+34) 976506644
} 


\section{ACRONYMS}
AWD All-wheel-drive traction system
ATEX Anti-explosion regulations
BEV Battery electric vehicles
ECU Electronic control unit
EM Electric machine of the BEV
EMS Energy Management Strategy
ESD Energy storage device
FCHV Fuel Cell Hybrid Vehicles
FPGA Field-programmable gate array
GSS Gas storage system
HPP Hybrid powerplant
ICE Internal combustion engine
ICEV Internal combustion engine vehicles
LED Light emission diodes
MEA Membrane electrode assembly
$\mathrm{NI} \quad$ National Instruments
PEMFC Polymer electrolyte membrane fuel cell
PLC Programmable logic controller
PV Photovoltaic panel arrays
PWM Pulse-width modulation
SOC State of charge of the battery system
ZEV Zero-emission vehicles 


\section{Introduction}

Today, about 60 million internal combustion engine vehicles (ICEV) are manufactured every year, and about a billion ICEV are circulating on the roads of our planet, representing one car for each seven people [1]. They are responsible for the emission of a very large part of the total amount of pollutants (solid particles, $\mathrm{CO}_{2}, \mathrm{NOx}$, $\mathrm{CO}, \mathrm{SO}_{2}$, etc.) contained in the air. The very nature of the combustion process impedes a significant reduction of these emissions in today's advanced ICEV. Modern societies are aware of the necessity of a cleaner air, which reflects in increasingly stricter emission legislations for both pollutants and greenhouse effect gases [2-4]. So, the development of new zero-emission vehicles (ZEV) to gradually substitute the ICEV in transportation is becoming urgent.

Most of the commercially available ZEV that are today accepted and promoted by the Governments of European Countries are pure electric vehicles powered with batteries (BEV). Ideally, the electricity which feeds this kind of vehicles should be obtained from renewable sources. Even if produced in large powerplants where heavy fuel oil is combusted, at least pollutants are emitted in basically much less populated areas, diminishing the negative health effect on human population. In any case, the main drawback of BEV is their limited range. A very interesting solution is to combine different power sources that can be connected either in serial, parallel, or serial-parallel configurations. This strategy is known as hybridization, and its implementation ensures high values of both energy and specific power [5]. The first hybrid powerplants (HPP) were based on ICEs, and achieved a significant reduction in fuel-oil consumption rates. As combustion products are still emitted, this configuration can only be considered as an intermediate stage towards the final ZEV objective. However, the optimal selection between BEV, hybrid ones or conventional ICEV, considering economic and environmental aspects is mainly dependent on the electricity cost and, into a lesser extent, on how clean it is produced [6-8].

Other solutions are based on hybrid electric architectures (real ZEVs), which are fed by an energy storage device (batteries or capacitors) and a fuel cell stack, which are usually called fuel cell hybrid vehicles (FCHV). The use of polymer electrolyte membrane fuel cells (PEMFC) in HPP offers a high efficiency and zero emissions (if the hydrogen is produced using energy from renewable sources) when compared to an ICE. It has the 
advantage of using hydrogen, which is the most efficient alternative to long-term energy storage of renewable production. Besides, due to the characteristics of batteries in terms of high energy density, compact size and reliability, these have been widely used in hybrid vehicles [9-11]. This is why FCHEV can be considered a solution for the increasing interest of car manufacturers, also extending the range of BEV. Nevertheless, to make this technology more profitable and affordable, some issues associated to hydrogen economy (production, distribution, storage, and refueling), PEMFC cost and lifetime, have to be improved [12,13].

In this paper, a commercial plug-in electric car was suitably modified to be powered by a hybrid powertrain based on PEMFC and batteries. The major drawback of PEMFC in transportation, the load handling capability during transients, is overcome by the existing battery set. This combination provides a good dynamic, increasing the lifetime of the stack and keeping the battery State of charge (SOC) within the safe limits $[14,15]$. It should also be noted that, as the electricity used to recharge the battery was produced using energy from renewable sources and the green-hydrogen was generated by water electrolysis, it can be actually considered a "real" ZEV.

\section{The electric vehicle}

This research is part of a project funded by the European Union under the LIFE program entitled "Profitable Small Scale Renewable Energy Systems in Agrifood Industry and Rural Areas: Demonstration in the Wine Sector" [16]. The surplus electricity produced by a stand-alone solar PV plant is eventually used to generate hydrogen in a production and refueling plant specifically assembled. According to the NREL [17], electrolysis is probably the most expensive method to produce hydrogen from a renewable source, especially when compared to biomass processing. Nevertheless, it was selected in this project due to the available excess electricity. The end-user of the resultant hydrogen is a commercial electric car, which was suitably modified to be powered by a hybrid powertrain based on a PEM fuel cell.

\subsection{The original battery electric vehicle (BEV)}

The commercial ePath-7500 car used in this project is an all-wheel drive (AWD) 4-seat plug-in BEV designed to travel on bumpy and irregular terrain, ideal for agricultural or 
industrial work regimes. A photo of this car is depicted in Fig. 1a). Originally, its $7.5 \mathrm{~kW}$ $72 \mathrm{~V} \mathrm{AC}$-electric motor was powered by a series of 12 gel-type $6 \mathrm{~V}, 225 \mathrm{~A}-\mathrm{h}$, battery bank. A $12 \mathrm{~V}$ battery block supplies energy to the ancillary systems, just as in conventional cars. The set of batteries is located under the rear seats of the vehicle. As specified by the manufacturer, when moving at a constant velocity of $30 \mathrm{~km} / \mathrm{h}$ over a flat and asphalted road, the car range is around $100 \mathrm{~km}$. An electric socket placed at the front side of the car allows recharging the batteries from the green-electric network. The total recharge time is around 8 hours. The BEV has a tilting load platform at the rear side where the fuel cell system (PEMFC stack, hydrogen storage and supply system, electric, electronic and control devices) was assembled.

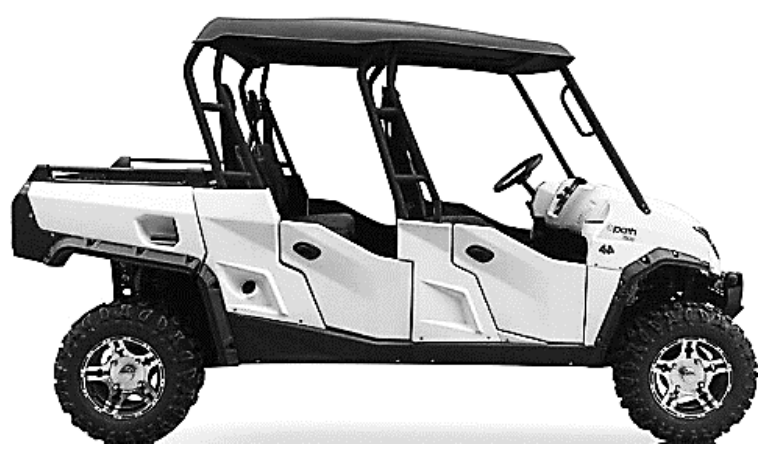

a)

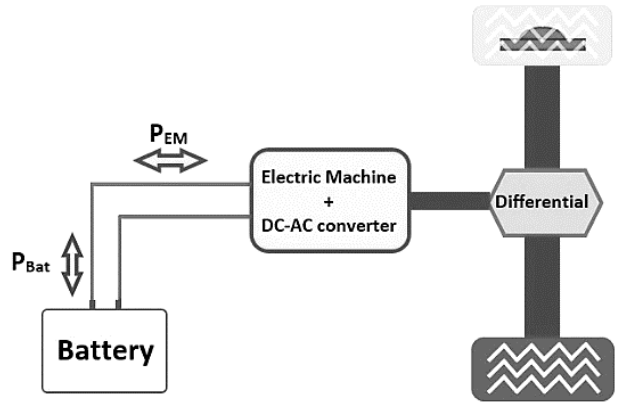

b)

Figure 1: The original ePath 7500 pure electric car (a) and its powertrain (b)

Concerning the powerplant of the original BEV (see Fig. 1b), the power from the battery set is supplied to the wheels by an electric machine (EM) through the differential. The EM is connected to the main DC bus through a DC/AC booster electronic converter. This device can also work as a generator, recovering energy when braking. The vehicle has three gears with manual shift, and the regenerative braking only works in the lowest gear.

\subsection{The hybrid electric vehicle (FCHEV)}

The commercial ePath-7500 BEV was suitably modified to be powered by a hybrid powertrain based on a PEM fuel cell and the original gel-type batteries. Several modifications were performed to adapt both the pure electric battery powertrain and the tilting rear load platform to include the commercial PEM fuel cell stack with its corresponding gas storage and supply system, as well as the electronic devices used for 
the hybridization. A picture of the modified vehicle is shown in Fig. 2.
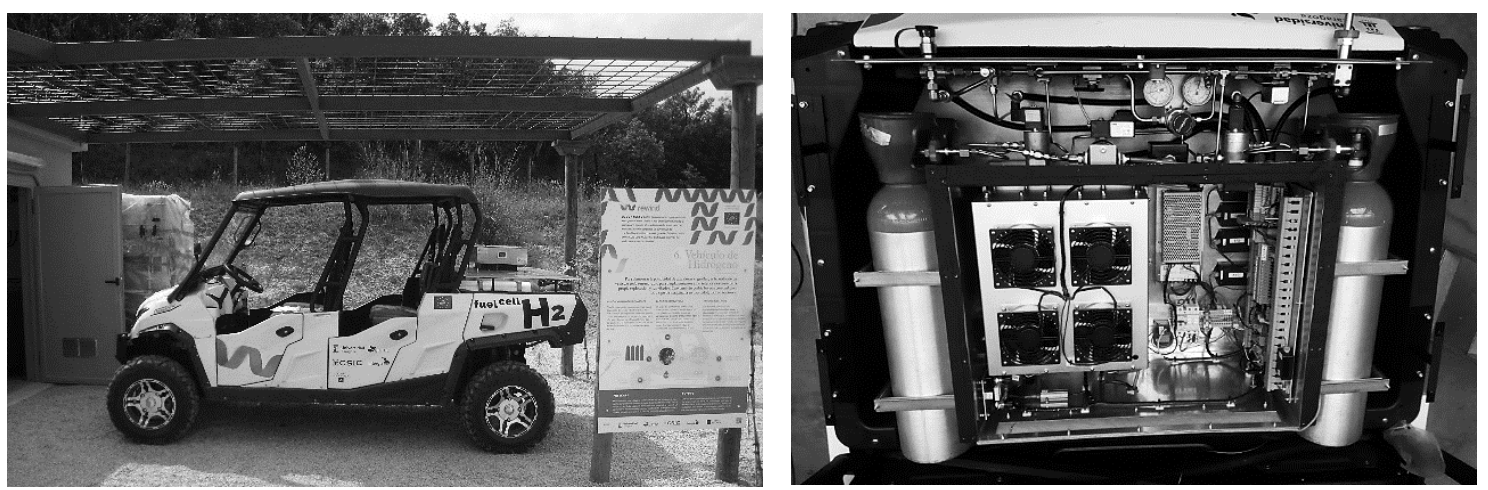

Figure 2. Two photos of the modified electric car with the $\mathrm{H}_{2}+\mathrm{PEMFC}$ system assembled at the rear platform

\subsubsection{The PEMFC stack}

A commercial $H-3000$ PEMFC stack, manufactured by Horizon and with a rated power of $3 \mathrm{~kW}$, was included as the second power source in the HPP. This is an opencathode stack formed by 72 cells with Nafion ${ }^{\circledR}$ membrane-electrode assemblies (MEAs) and graphite bipolar plates, which includes 4 axial fans to move the air needed both to ensure the oxygen for the electrochemical reactions and to cool the stack down to the working temperature $\left(50-65^{\circ} \mathrm{C}\right)$. Dry hydrogen with a purity of $99.999 \%$ coming from the electrolyzer was supplied at a working pressure of 0.5 bar. Its total weight is $15 \mathrm{~kg}$ and its volume is 26 liters, yielding a specific nominal power of $200 \mathrm{~W} \mathrm{~kg}^{-1}$ and a nominal power density of $115.38 \mathrm{~W} \mathrm{I}^{-1}$. As reported by the manufacturer, at the rated power (70

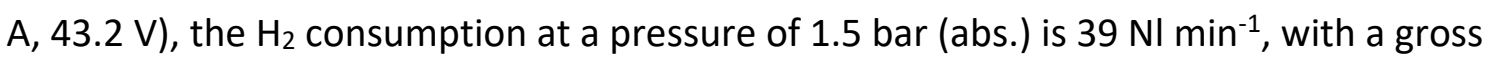
efficiency of $47.04 \%$, which decreases to $40 \%$ when the power consumed by the control system and the ventilation system are considered. On the other hand, the start-up time, at room temperature, is below 30 seconds. Two polarization curves of the stack obtained in the test bench can be observed in Fig. 4, one for increasing current (lower) and the other decreasing from the maximum value (upper). To avoid damaging the stack, the manufacturer recommends that it should never work below $36 \mathrm{~V}$ or generate more than $90 \mathrm{~A}$. Accordingly, an optimal current density of $285 \mathrm{~mA} \mathrm{~cm}^{-2}$ has been considered. At this point, marked in Fig. 3, the stack will generate $56.2 \mathrm{~A}$ at $44.5 \mathrm{~V}$, corresponding to a power yield of 2,500 $\mathrm{W}$ (or a power density of $12.54 \mathrm{~W} \mathrm{~cm}^{-2}$ ), and a measured hydrogen consumption of $32 \mathrm{NI} \mathrm{min}^{-1}$. It has also been established that the 
current produced by the stack will never exceed $65 \mathrm{~A}(45.8 \mathrm{~V})$, which translates into a

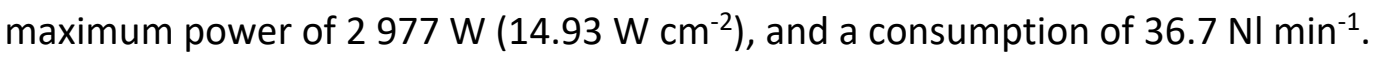

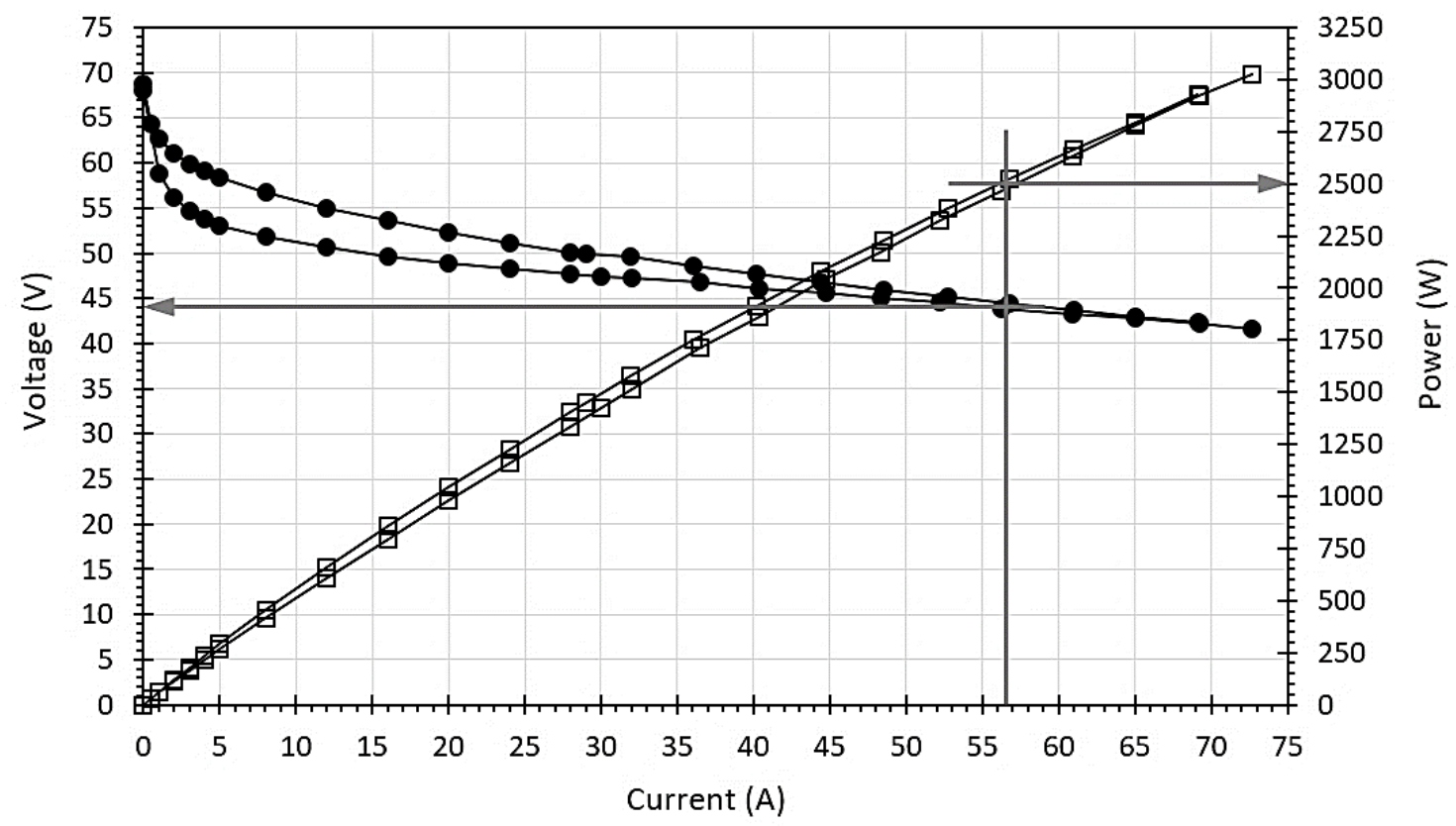

Figure 3. Initial polarization curve obtained for the $\mathrm{H}-3000$ in the test bench

\subsubsection{The hydrogen supply system of the FCHEV}

The hydrogen to be used by the PEMFC stack in the HPP is stored in four aluminum cylinders with a geometric volume of 10 liters and a weight of $12.75 \mathrm{~kg}$ each. Therefore, the total volume of hydrogen that can be stored at 200 bar considering a compression factor of 1.132 is $7.06 \mathrm{~m}^{3}$, which corresponds to $0.64 \mathrm{~kg}$ or, in energy terms, to $21.3 \mathrm{kWh}$. All the elements and devices of the gas supply system have been assembled in two panels placed at the modified rear tilting platform. Different solenoid valves control both the supply of hydrogen to the stack and its refueling to the GSS, as depicted in the piping and elements diagram of Fig. 4. Instruments and devices that fulfill anti-explosion (ATEX) requirements are also identified.

Hydrogen is refueled to the GSS of the FCHEV with a simple and innovative system either automatically through nozzle Bo1 (commercial WEH ${ }^{\circledR}$ system) or manually using connector Bo2. All elements and devices of the hydrogen supply system to the PEMFC stack fulfill ATEX regulations as is mandatory for these facilities. In the present research, two unidirectional solenoid valves (one for each two bottles, as depicted in Fig. 4) of small internal diameter, capable of supporting high pressures, have been placed in parallel with non-return valves, instead of the bidirectional large opening solenoid 
valves that are commonly used. The solenoid valve is only used to supply the hydrogen to the PEMFC stack (i.e. to discharge the GSS). The refilling of the bottles is carried out through the non-return valves that have a very high flow rate (large internal diameter). They are automatically opened by simple pressure difference. In this way, the refilling time of the GSS is very short and the whole process is very efficient. The commercial refueling $\mathrm{WEH}^{\circledR}$ system is formed by the TK-16 nozzle and the TN-1 receptacle, and integrates a high-flow check valve and a self-cleaning particle filter (20 micron).

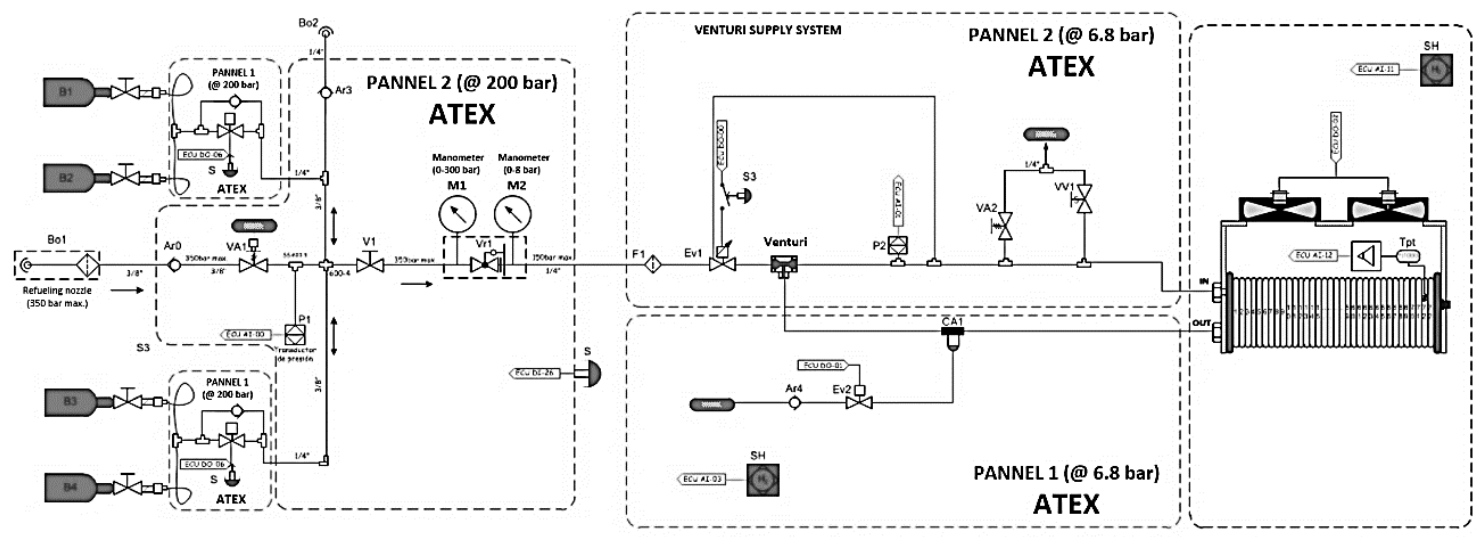

Figure 4. Piping and elements diagram of the hydrogen storage and supply system

To supply hydrogen to the PEMFC stack, the system includes a $0.5 \mu \mathrm{m}$ particulate filter (F1) and a recirculation system formed by a proportional solenoid valve (Ev1) and a Venturi-type ejector. This element allows the recirculation of part of the unreacted hydrogen from the anode sides and to reintroduce it into the stack. Passive or active hydrogen recovery schemes have been used previously in both constant hydrogen bleed or hydrogen purge strategies [18-24]. To this end, hydrogen blowers, recirculation pumps or Ventury-type ejectors are included at the anode gas line. In the ejector, the velocity of the inlet gas increases as it passes through the nozzle while its pressure decreases, allowing the suctioning of the recirculated gas. When the hydrogen is consumed in the stack, the inlet pressure tends to decrease below the set point 0.5 bar). Then, the proportional solenoid valve, which is controlled by the pressure measured at the Venturi outlet, causes a proportional increase in the gas, keeping a constant hydrogen pressure of 0.5 bar at the stack. To ensure a stable operation of the PEMFC for all working conditions, the pressure of Ev1 varies from 0 to 4.4 bar. Another filter (CA1) was also placed in the line in order to collect the impurities dragged by the 
recirculated gas. Impurities (water and nitrogen) are eventually eliminated from this filter by purges performed at a given frequency depending on the current demanded to the stack [25-28]. The recirculation system is passive, and does not imply any power consumption.

\subsubsection{The active hybrid powertrain}

The $\mathrm{H}_{2}+\mathrm{PEMFC}$ powerplant was added to the original electric one included in the vehicle forming the HPP. This corresponds to the elements enclosed in the dashed square of the final configuration diagram depicted in Fig. 5 a). The electrical layout with the different elements is shown in Fig. 5 b).

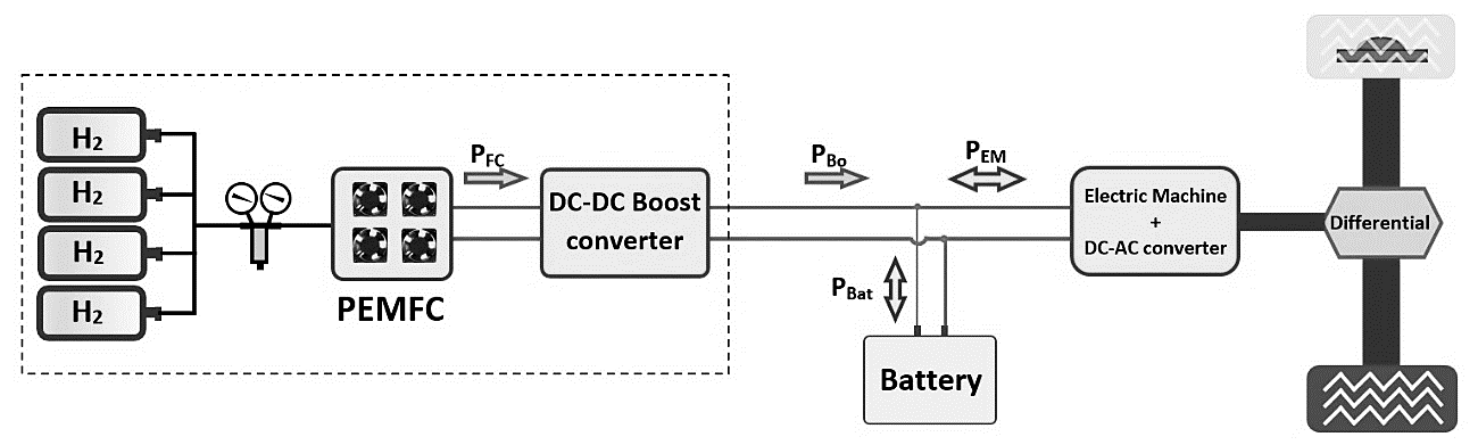

a)

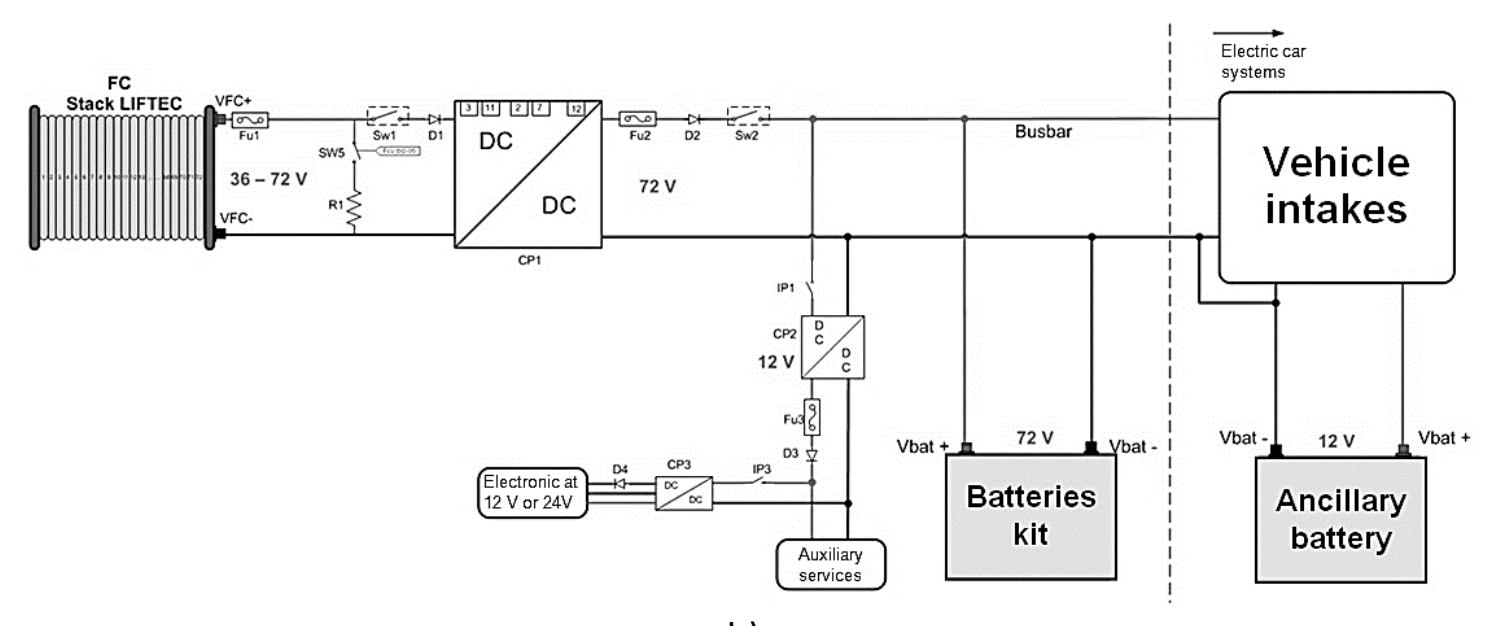

b)

Figure 5. Hybrid powerplant of the FCHEV: a) diagram of the final configuration with the added $\mathrm{H}_{2}+\mathrm{PEMFC}$ system (dashed square); (b) electrical layout

The aim of the active hybrid system is to safely supply the electric power produced in the PEMFC stack to the main DC bus of the BEV (Busbar) using a booster DC/DC power converter (CP1). Two other DC/DC converters are used to supply power at $12 \mathrm{~V}$ and 24 
$V$ to the different electric and electronic elements of the ancillary systems of the $\mathrm{H}_{2}+\mathrm{PEMFC}$ system. In the hybrid system, the voltage at the Busbar is fixed by the battery, varying from $78.3 \mathrm{~V}$ (when the battery set is fully charged) to $69 \mathrm{~V}$ (when the SoC is around $30 \%)$. Therefore, the booster DC/DC converter (CP1) is current controlled, a different strategy from the one used in [29] where the device was voltage controlled, meaning that it can only supply power to the Busbar when the SoC of the battery is below 95\% (75.9 V). As can be observed in Fig. 5 b), different switches, fuses and protection diodes are included, in order to ensure the safe operation of the hybrid powerplant. If a problem occurs during the PEMFC stack operation, the power switch (Sw1) opens, and the relay Sw5 that powers the resistor (R1) is activated, preventing the degradation of the stack when operating at open circuit voltage [30]. R1 is also used to consume all the hydrogen remaining in the stack during the stop protocol of the PEMFC stack.

\subsubsection{The control system and energy management strategy}

In general, designing an efficient control system for a PEMFC is challenging due to its sluggish dynamics, nonlinearity and strict operating constraints. A sudden change in power load causes a significant drop in the stack hydrogen partial pressure (starvation), which rapidly decreases the cell voltage, shortening the lifetime of the device. Thus, the control system has to be capable of ensuring that the PEMFC satisfies the dynamic load with the maximum operating efficiency. Many of the degradation mechanisms that occur in both PEMFC and batteries are strongly linked to the operating conditions and therefore can be mitigated by optimizing the Energy Management Strategy (EMS). In this way, the overall efficiency of the system is also maximized [31-33]. The commercial $\mathrm{H}-3000$ stack is supplied with its own control system. However, due to the specificities of this application (e.g. the inclusion of the hydrogen recirculating system) and to increase as much as possible the lifetime of the stack, it was decided to replace the commercial electronic control by one accordingly designed. To control and monitor the different electrical parameters of the $\mathrm{H}_{2}+$ PEMFC system, a central electronic control unit (ECU) was used. It consists in an embedded control and acquisition $\mathrm{NI}$ roboRIO microcontroller with a real-time dual-core ARM Cortex-A9 processor and a Xilinx Z-7020 FPGA. It is a reconfigurable robotic controller that meets industrial shock and vibration 
standards. This ECU includes built-in ports for inter-integrated circuits $\left(I^{2} C\right)$, serial peripheral interface (SPI), RS232, USB, Ethernet, PWM and relays. It features LEDs, buttons, an onboard accelerometer and a custom electronics port. The LabVIEW control software regulates the sampling frequency to $800 \mathrm{~Hz}$.

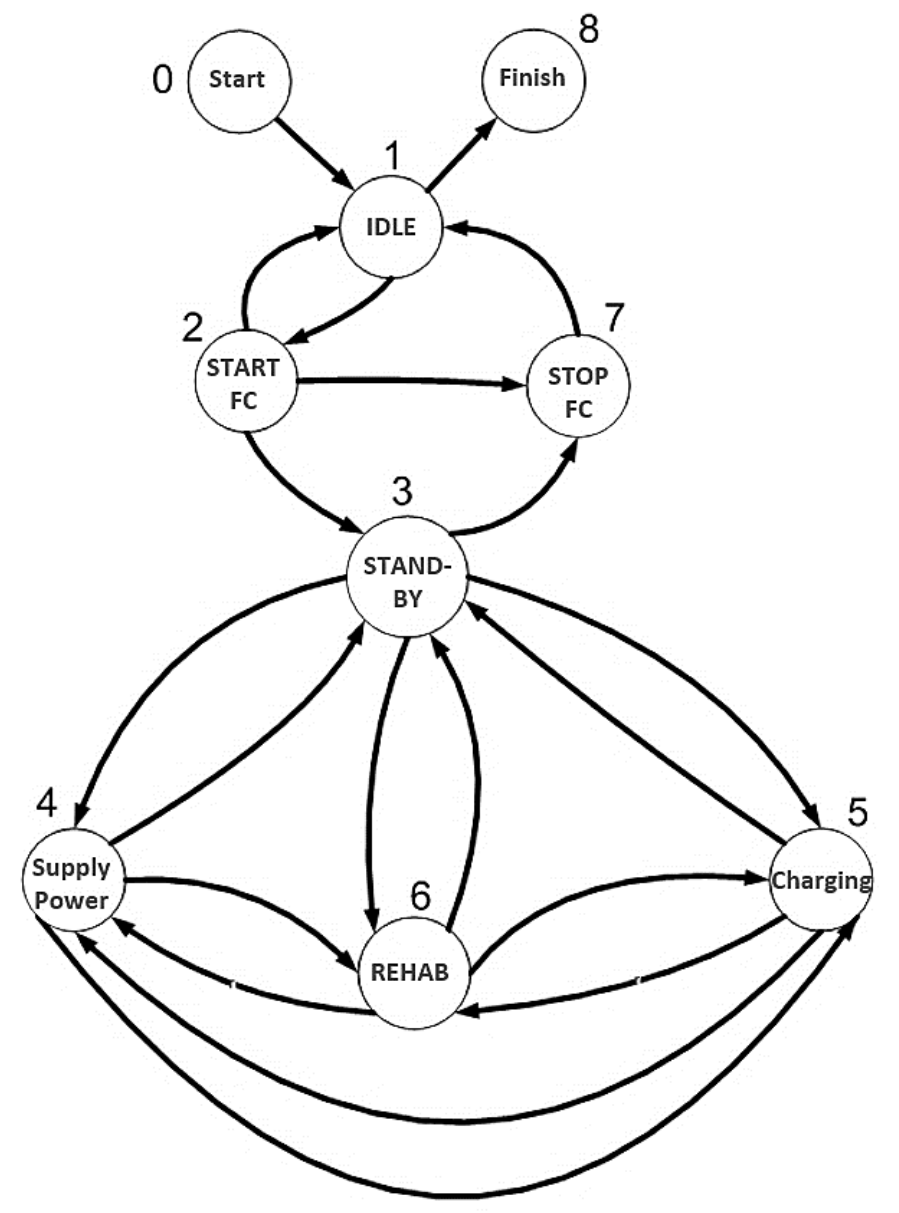

Figure.6. Diagram of the operating modes of the state machine used to control the stack performance

The control system of the stack includes, as a novelty in PEMFC applications, a discrete state machine model programmed in LabVIEW code with LINUX realtime operating system, which was embedded into the ECU microcontroller. The control model, as can be observed in the diagram of Fig. 6, follows a ruled-based approach where the transition among the different operating modes, such as STAND-BY, SUPPLY POWER, CHARGING, etc., is decided by a state machine that is based on vehicle operating conditions, change in driver demand, and any system fault that can be detected $[34,35]$. The initial mode, START $(0)$, is a transient state where all operating parameters are reset. After that, the stack immediately goes into the IDLE mode (1), 
waiting until the "fuel cell ON" button is pressed (START FC mode). If, due to a problem, either the stack cannot be turned-on or it does not work properly, it will return to IDLE, and some visual alerts (LEDs) are lighted up. If the fuel cell is switched on correctly, it jumps to STAND-BY mode (3), where the stack only generates the power consumed by the control electronics and the ancillary systems. Once in this state, the stack is ready to either supply power to the EM of the vehicle or to recharge the battery system.

Three different situations are considered. On the one hand, when the vehicle operates in a low consumption rate and the SoC of the battery is below $95 \%$, the stack is switched to CHARGING mode (5). On the contrary, if the power demanded at the main DC bus increases, it is shifted to the SUPPLY POWER state (4). The control system was designed to ensure an almost constant power delivered by the PEMFC, while the battery system provides the additional power required for acceleration. So, the $\mathrm{H}_{2}+\mathrm{PEMFC}$ system acts as a range extender of the original BEV. When the PEMFC stack works properly, it alternates between CHARGING and SUPPLY POWER modes. In order to check the correct operation of the stack, a typical polarization curve was also recorded into the microcontroller. Nevertheless, if it is observed that for a given current the voltage delivered by the PEMFC departs $10 \%$ from the one corresponding to that of the recorded polarization curve, it enters in the rehabilitation (REHAB) mode (6). The aim of this mode is to improve (or recuperate) the correct performance of the PEMFC, eliminating the water and nitrogen accumulated inside the stack activating the purging strategy, since the commercial $\mathrm{H}-3000$ operates in dead-end mode. Usually, after the purging sequence the performance of the stack is recovered and it is again moved to SUPPLY POWER or CHARGING modes, depending of the total power demanded by the vehicle. On the contrary, if after the purging sequence the performance of the stack is not improved, the alarm LEDs are lighted up again, and the stack is sequentially moved to STAND-BY, STOP FC (7) and IDLE states. Eventually, it is shifted to the FINISH mode (8), stopping the hybrid control sequence.

Additionally, the internal 3-axis accelerometer of the $\mathrm{NI}$ roboRIO is used either to calculate the inclination of the vehicle, or to identify if it has undergone a sudden acceleration or an abrupt deceleration caused by an accident. In that case, the electrical signal produced by this device cuts off the main hydrogen supply system. 


\section{Results}

The results discussed in this section were obtained in different field tests performed during the use of the FCHEV in real operating conditions at Viñas del Vero winery.

\subsection{Performance of the PEMFC stack}

Once the hydrogen system (GSS, $\mathrm{H}_{2}$ supply system, PEMFC stack, and control electronics) was fully assembled in the vehicle, the performance of the $\mathrm{H}_{2}$ recirculation system was verified. The polarization curve and the hydrogen consumption directly measured are depicted in Fig. 7. As can be observed, the use of the Venturi recirculating system slightly improves the performance of the FC. If this performance is compared with that initially obtained in the test bench (see Fig. 3), it is observed that a lower current is needed to supply the power corresponding to the rated operating point ( 2.5 kW). Then, hydrogen consumption also decreases, and the actual efficiency (47.9\%) of the $\mathrm{H}-3000$ is increased close to $1 \%$. It is also important to note that a better performance is also obtained when the stack works in the CHARGING operating mode. For this mode, the current delivered by the stack with the Venturi system for the demanded power $(1.4 \mathrm{~kW})$ is $27.5 \mathrm{~A}$, and the hydrogen flowrate is $15.3 \mathrm{NI} \mathrm{min}^{-1}$, yielding an efficiency of $55.51 \%$. On the contrary, for the original system, for the same operating point the current provided is $29 \mathrm{~A}$, the hydrogen consumption is $16.34 \mathrm{NI} \mathrm{min}^{-1}$, and the efficiency falls down to $51.98 \%$.

In the present research, the importance of the passive hydrogen recirculating has been demonstrated. During dead-end anode operation, impurities (liquid water and nitrogen gas) are transported through the membrane from the cathode to the anode side. This accumulation causes a decrease in the hydrogen partial pressure and also may block hydrogen gas from reaching the anode catalyst layers. This, in turn, leads to local hydrogen starvation that can result in corrosion of the carbon support, a decrease in cell performance, and finally, irreversible cell degradation [36-39]. With the purge strategy, the water and nitrogen accumulated are swept out and replaced by fresh dry hydrogen improving the fuel utilization rate. This system also helps to control the cell voltage. This is very important, especially in the low current density range, avoiding the irreversible corrosion damage of the carbon support due to an uncontrolled voltage increase. Finally, this system also allows the self-humidification of the stack, avoiding the use of 
an external humidifier.

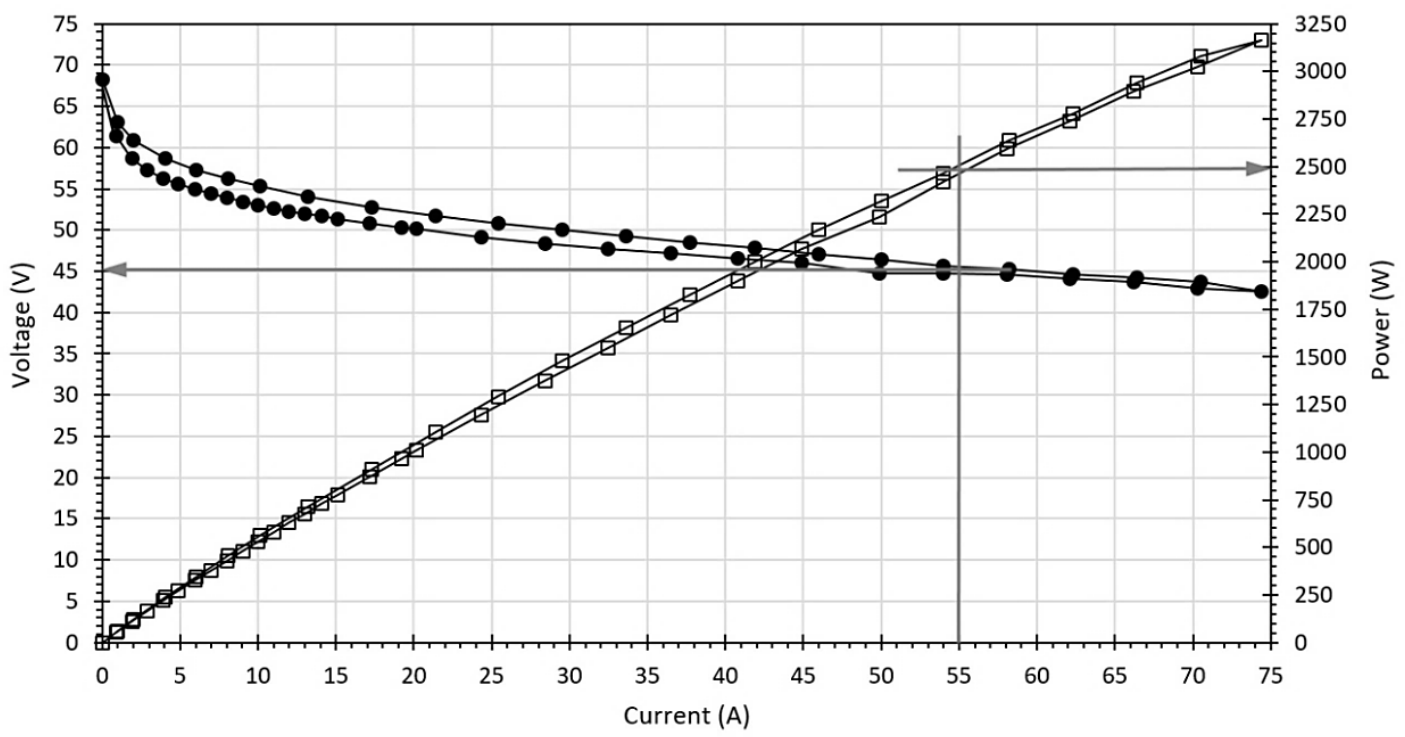

a)

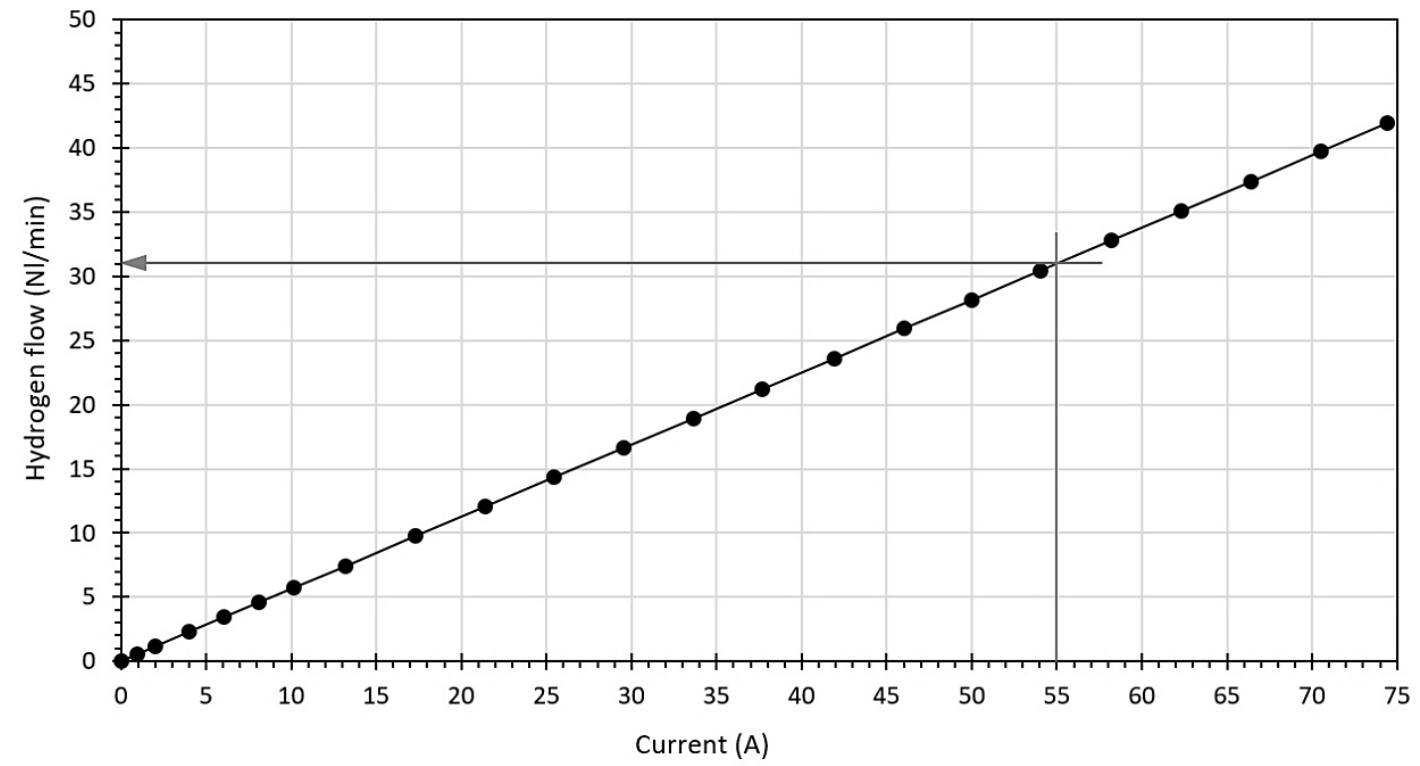

b)

Figure 7. Polarization curve (a) and hydrogen consumption (b) of the $\mathrm{H}-3000$ with the hydrogen recirculating system for the nominal operating point ( $2.5 \mathrm{~kW})$.

In the field tests performed at the winery, it was verified that there are some factors that affect the behavior of the PEMFC stack. The most relevant ones are the position in which stack is assembled, the head losses in the air circuit, and the ambient temperature. It was also demonstrated that the influence of the pressure losses introduced at the hydrogen supply system is very low and can be neglected. For the assembling position, the manufacturer recommends to place the stack vertically in order to facilitate the extraction of the water produced in the electrochemical reactions. 
Regarding the air circuit, a filtering material with low pore size was placed at the air inlet port, to prevent the entry of dust into the cathode channels, which could seriously damage the MEAs. To overcome the added pressure loss, the working voltage of the axial fans was carefully optimized. Finally, in tests performed during winter, it was noted that when the ambient temperature was close to $5^{\circ} \mathrm{C}$, which is usual in the winery, the stack temperature during the operation was in the lowest limit established by the manufacturer.

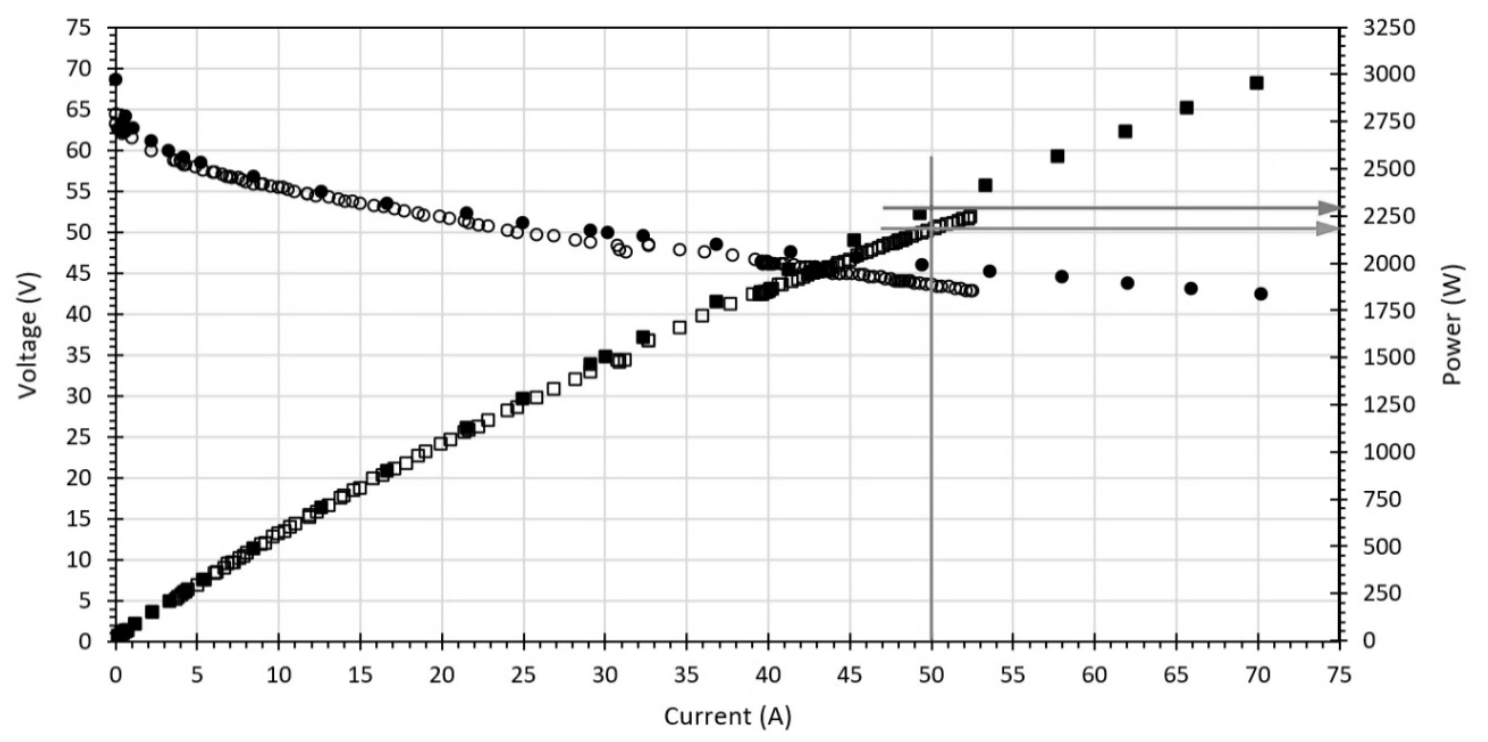

Figure 8. Comparison of the performance of the PEMFC stack: Initial (solid symbols) vs. 1,000 hours at the winery operating conditions (empty symbols)

In Fig. 8, the performance of the stack registered at the winery after 1,000 h (empty symbols) and the initial polarization curve obtained at the test bench (solid symbols) are compared. As it can be observed, the power difference for the same operating point (50 A) with respect to the value obtained in the test bench is about $110 \mathrm{~W}(4.8 \%)$. The main part is attributed to the different operating conditions between both the laboratory and the field tests. When the polarization curve was obtained at the test bench, the stack voltage was stabilized for each demanded current. On the contrary, in the field tests the stack reacts dynamically to the power demand of the vehicle user, as it happens in real life. Besides, as the field tests were performed in May with an optimal ambient temperature $\left(25^{\circ} \mathrm{C}\right)$, the low performance can only be attributed to the assembling position, and to the head losses at the air circuit. 


\subsection{Performance of the hybrid electric car}

The results obtained during a real driving test are depicted in Fig. 9. It consisted in a round trip from the parking of the winery to the closest vineyards at a distance of 3.5 $\mathrm{km}$, climbing two small hills (40 m), as can be observed in the altitude profile (solid line) in Fig. 9 a). The velocity profile is also plotted with the dotted line. The average velocity of the FCHEV during the whole test was $15.6 \mathrm{~km} / \mathrm{h}$, reaching a maximum of $43 \mathrm{~km} / \mathrm{h}$. It was calculated that the average power demanded by the EM of the vehicle was $3.75 \mathrm{~kW}$. However, as can be observed in Fig 9 b), the peak power demanded by the vehicle (solid black line) exceeds, by far, the EM rated power (horizontal dashed grey line). This corresponds to the ascension of the hills or when a fast acceleration is demanded. In this situation, the control systems limited the power supplied by the PEMFC stack to the EM of the vehicle to a maximum of $30 \%(2.5 \mathrm{~kW})$ of the rated one $(7.5 \mathrm{~kW})$. It was also verified that for the high demand range, the power is mainly supplied by the battery (dotted grey line), while for the low power demand range the CHARGING mode at the $\mathrm{H}-3000$ stack is activated and part of the energy is used to recharge the battery. This situation corresponds to the zones in Fig. 9 b) where the power of the battery is negative. In this case, the stack supplies $1.4 \mathrm{~kW}$ (power density of $7.02 \mathrm{~W} \mathrm{~cm}^{-2}$ ) to the DC-DC converter; $1.14 \mathrm{~kW}\left(5.72 \mathrm{~W} \mathrm{~cm}^{-2}\right)$ of them are used to recharge the battery, due to the efficiency of the electronic elements for the operating point (92.8\%) and the low power needed for the ancillary systems $(160 \mathrm{~W})$. The rest of the power of the stack is used in the control electronic devices. Besides, it is also important to highlight that during both start-up and before stopping the vehicle, the total energy demanded by the EM is supplied by the PEMFC stack.

On the other hand, the PEMFC stack operates in a quasi-steady state (solid bold grey line), with an average power of $1.27 \mathrm{~kW}$ and a net efficiency of $52.02 \%$. As depicted in Fig. 9 c), very low variations of both voltage and current delivered by the stack were detected, except for the region "I" surrounded by the square in Fig. 9 b), which corresponds to the running time between $590 \mathrm{~s}$ and $645 \mathrm{~s}$. This behavior coincides with the recovery of electric energy from braking that took place (in this test) when descending the second hill and the vehicle traction system was shifted to the lowest gear. It was also confirmed that, when working in hybrid mode, $66 \%$ of the total energy demanded by the vehicle was supplied by the battery, and $34 \%$ by the PEMFC. 


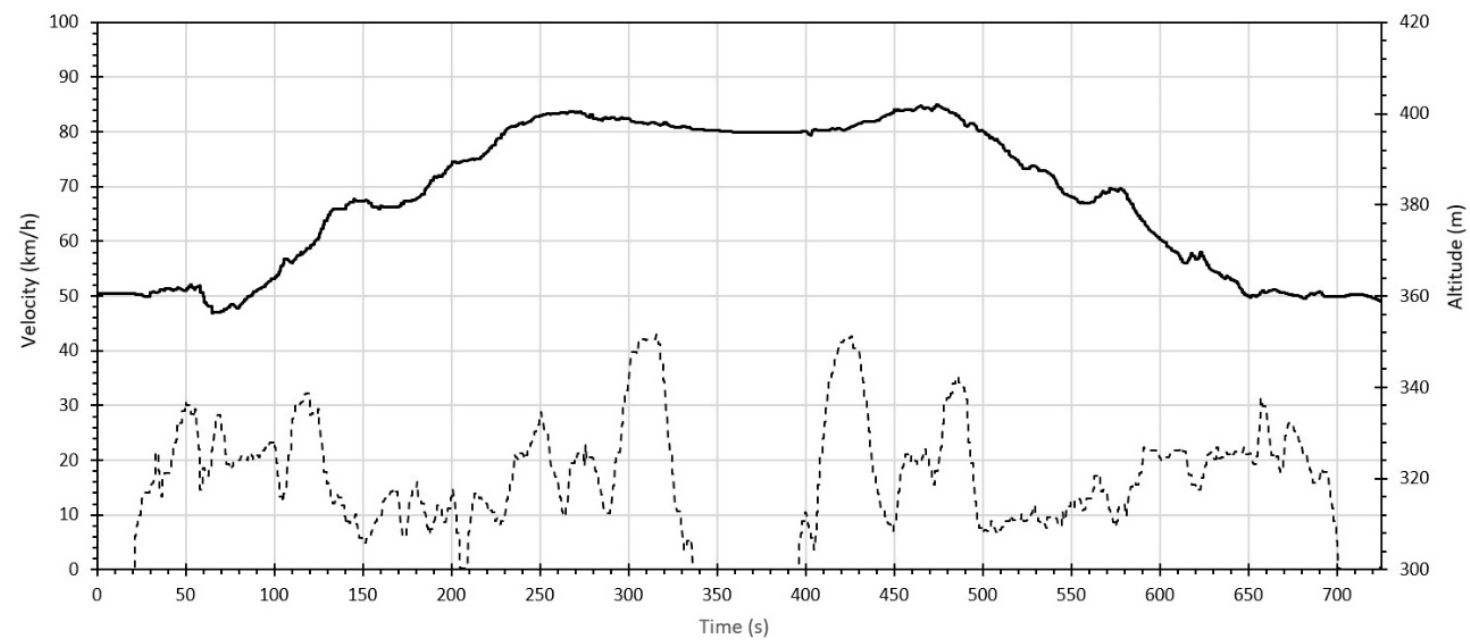

a)

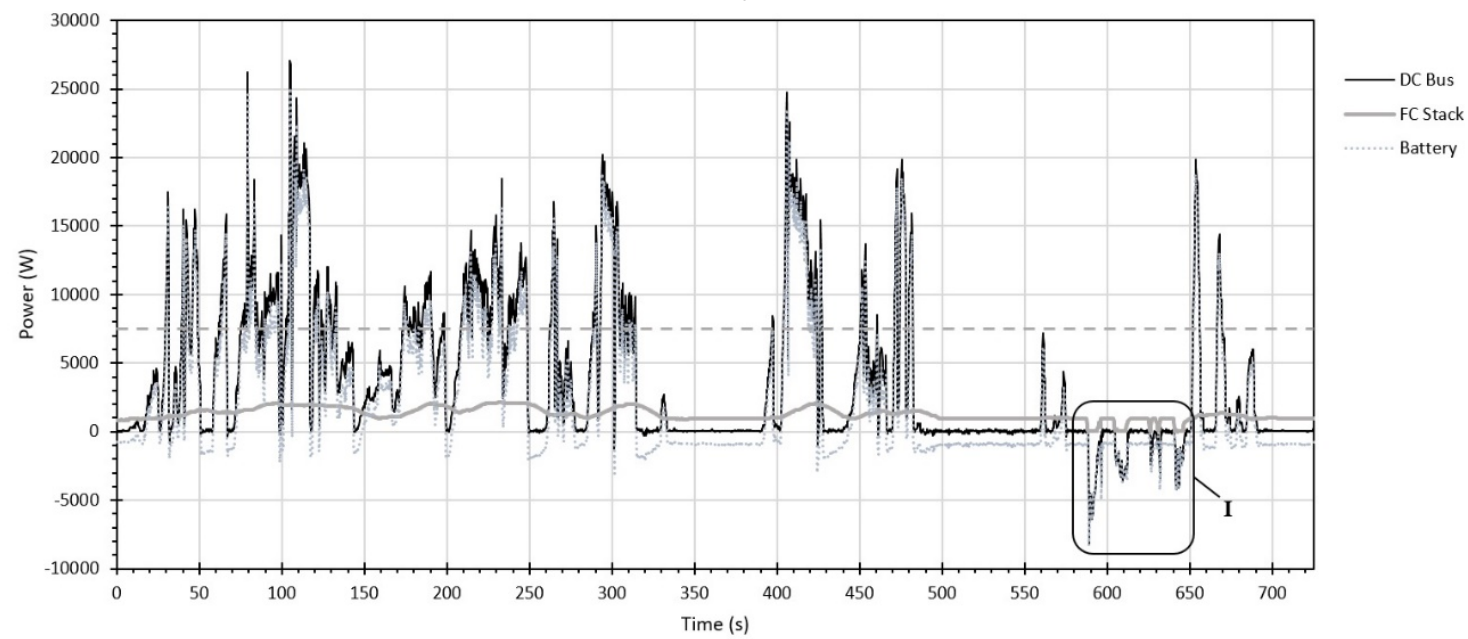

b)

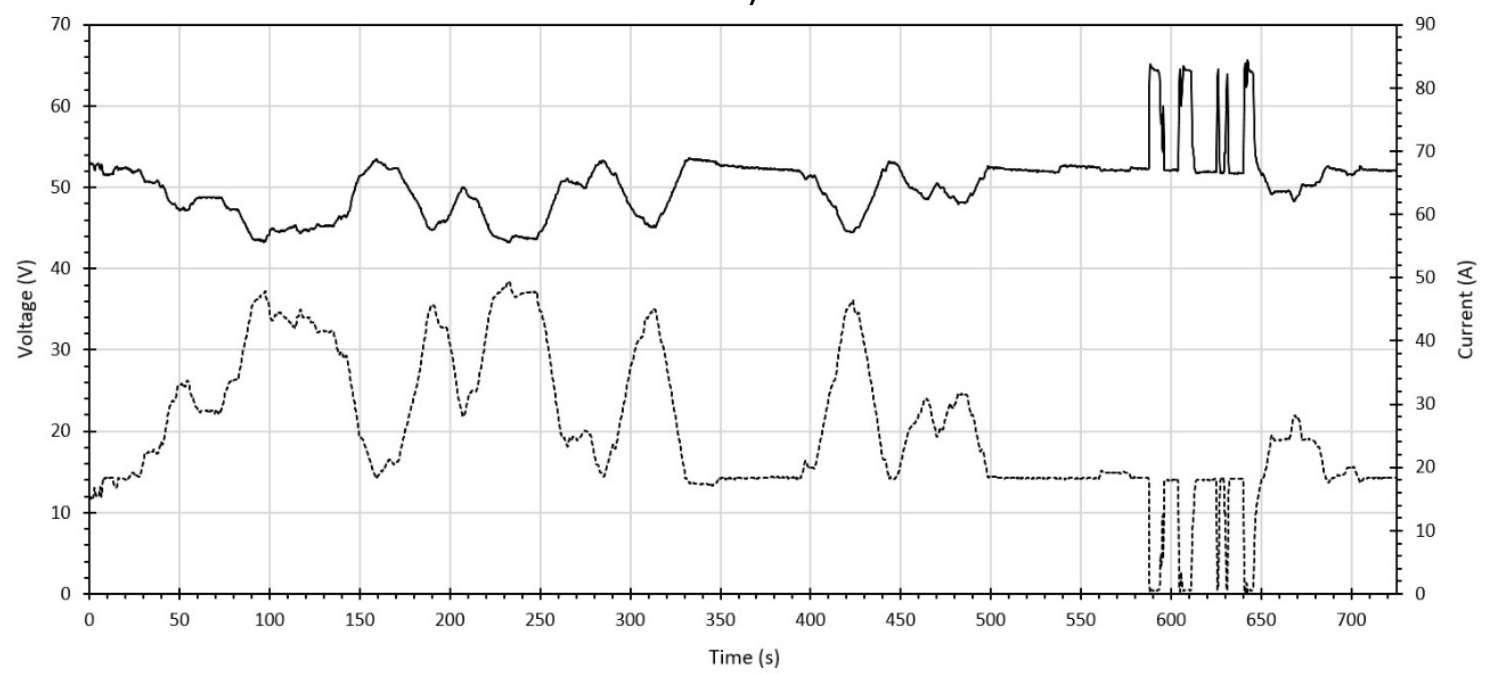

c)

Figure 9. Results of the real driving test in the winery: a) Altitude (solid line) and velocity profiles (dotted line), b) Power of the different sources, and c) Electric performance of the stack (voltage in solid line and current in dotted one) 
When running in the bumpy and irregular terrain of the winery, the operating time of the pure electric vehicle (without the use of the hybrid powerplant) was verified to be close to 2.7 hours until the minimum SoC of the battery set was achieved (below $25 \%)$. As recommended by the manufacturer the state of charge of the battery should never be less this limit because it can be very harmful, and its lifetime is drastically reduced. This means that the actual range of the $B E V$ is lower than $80 \mathrm{~km}$. On the contrary, when the hybrid system was used, to the energy stored in the set of batteries (40.9 MJ), a net energy of $30.88 \mathrm{MJ}$ (actual energy output from the booster DC/DC converter) was added by the PEMFC stack, and the FCHEV was able to run during 4.8 hours. So, the actual range of the vehicle when using the hybrid powerplant is extended $78 \%$ compared to the original BEV. This is very important because the range of the hybrid vehicle does meet the requirements of daily range imposed by the winery, which, according to the tasks assigned, should be more than 4 hours. The possibility to perform an electric recharge during the day to meet this requirement was neglected because the commercial charger of the vehicle is very slow. Actually, the time needed to complete a full electrical recharge is above 8 hours. However, the hybrid system increases the autonomy up to 4.8 hours with the hydrogen contained in the GSS of the vehicle. However, if for any reason the working time needs to be further extended, the hydrogen refueling system allows to refill the GSS of the vehicle in less than 20 seconds.

It should also be highlighted that the significant increase in the autonomy of the FCHEV verified in the actual field tests has been possible by the implementation of the stack control system and energy management strategy. The transition among the different operating modes (STAND-BY, SUPPLY POWER, CHARGING, etc.) is decided depending on the vehicle working conditions, change in driver demand, and on any system fault that can be detected. The operation strategy imposed by the designed control system, ensures that the PEMFC stack always works in a range very close to the maximum efficiency and minimum fuel consumption operating point. The inclusion of the rehabilitation mode (REHAB) in the control system has allowed to improve the performance of the stack and to increase its lifetime. All the improvements incorporated to the hybrid vehicle have allowed its operation for more than 1,000 hours during the first year of the project without a noticeable loss of performance. So the validity of the EMS implemented in the control system has also been demonstrated. 
Finally, the energy management strategy of the hybrid powerplant also allows to increasing the useful lifetime of the batteries. In general, as already discussed, the PEMFC stack supplies $30 \%$ of the power demanded by the EM if it is close to the rated one $(7.5 \mathrm{~kW})$, and all of the total when it is lower than $2 \mathrm{~kW}$. This situation enables to establish a less aggressive operating strategy for the batteries, allowing prolonged inactive intervals that help to cool them down, avoiding deep energy discharge, and reducing its degradation.

\section{Conclusions}

A commercial plug-in ePath-7500 BEV has been suitably modified to be powered by a hybrid powertrain formed by a commercial H-3000 PEMFC stack that increases $78 \%$ the initial range of the BEV. The PEMFC system (electric and electronic control, hydrogen storage, and the stack) was assembled at the original tilting rear load platform. The hydrogen supply system includes a proportional solenoid valve and a Ventury-type ejector that allows the recirculation of part of the unreacted hydrogen from the anode sides. Polarization curves of the stack show that its performance slightly improves when the hydrogen recirculation system is used. It is verified that for the rated operating point $(2.5 \mathrm{~kW})$ the hydrogen consumption decreases, and the actual efficiency (47.9\%) PEMFC is increased close to $1 \%$ when compared to the results obtained in the test bench. Besides, an optimum state machine model has been integrated in the control system of the PEMFC stack. The inclusion of a rehabilitation operating mode ensures the safe operation of the stack, enlarging its lifetime. A better performance of the stack is also obtained when the stack works in the CHARGING operating mode. For this mode, the current delivered by the stack for the demanded power $(1.4 \mathrm{~kW})$ is $27.5 \mathrm{~A}$, and the

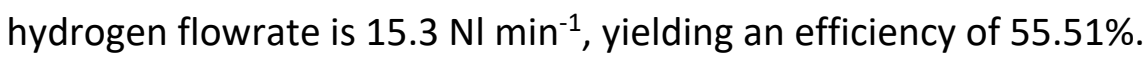

Field tests performed proved that when working in hybrid mode $34 \%$ of the total energy demanded by the vehicle was supplied by the PEMFC stack. During the demonstration period (237 day) the vehicle has efficiently operated in hybrid mode for more than $1,000 \mathrm{~h}$, confirming the validity of the EMS implemented in the control system, which also extends the lifetime of the battery set. The excellent performance of the refueling system was also verified, refilling the GSS of the FCHEV in a very short time. 


\section{Acknowledgements}

This work has been funded by the European Union LIFE+ under project LIFE13 ENV/ES/000280, and by the Secretariat of State for Research of the Spanish Ministry of Economy and Competitiveness under project DPI2015-69286-C3-1-R (MINECO/FEDER, UE). Support of the Regional Government of Aragon to the Experimental Fluid Dynamics Research Group (TO3) of the LIFTEC is also acknowledged.

\section{References}

[1] A.K. Shukla, C.L. Jackson, K. Scott, The Promise of Fuel Cell-based Automobiles, Bulletin Material Science (2003), 207-214

[2] IPCC Fifth Assessment Report, Climate Change: The Physical Science Basis, Summary for Policy Makers, Technical Report, IPCC (2013)

[3] Transport Energy and $\mathrm{CO}_{2}$, Technical Report, International Energy Agency (2009)

[4] $\mathrm{CO}_{2}$ Emissions from fuel combustion, Technical Report, International Energy Agency (2015)

[5] T.J. Gross, A.J. Poche Jr, and K. C. Ennis, Beyond demonstration: the role of fuel cells in DoD's energy strategy, Technical Report, DTIC Document (2011)

[6] H. Huo, H. Cai, Q. Zhang, F. Liu, K. He, Life-cycle assessment of greenhouse gas and air emissions of electric vehicles: a comparison between China and the US, Atmospheric Environment 108 (2015) 107-116

[7] N.C. Onat, M. Kucukvar, O. Tatari, Conventional, hybrid, plug-in hybrid or electric vehicles? State-based comparative carbon and energy footprint analysis in the United States, Applied Energy 150 (2015) 36-49

[8] M. Roth, Lifetime costs, life cycle emissions, and consumer choice for conventional, hybrid and electric vehicles, in: Transportation Research Board $94^{\text {th }}$ Annual Meeting, (2015) 15-5314

[9] J. Huang, D. Quin, Z. Peng, Effect of energy-regenerative braking on electric vehicle battery thermal management and control method based on simulation investigation, Energy Conversion and Management 105 (2015) 1157-1165

[10] F. Hassan, Fuel cell/back-up battery hybrid energy conversion systems: dynamic modeling and harmonic considerations, Energy Conversion and Management (2015) 573-584 
[11] W. Jiang, B. Fahim, Active current sharing and source management in fuel cellbattery hybrid power system, IEEE Trans. Industrial Electronics 57 (2010) 752-761

[12] N. Sulaiman, M. Hannan, A. Mohamed, E. Majlan, W. W. Daud, A review on energy management system for fuel cell hybrid electric vehicle: Issues and challenges, Renewable and Sustainable Energy Reviews 52 (2015) 802-814

[13] B.G. Pollet, I. Staffell, J.L. Shang, Current status of hybrid, battery and fuel cell electric vehicles: From electrochemistry to market prospects, Electrochimica Acta 84 (2012) 235-249

[14] K.C. Bayindir, M.A. Gozukucuc, A. Teke, A comprehensive overview of hybrid electric vehicle: powertrain configurations, powertrain control techniques and electronic control units, Energy Conversion and Management 52 (2011) 1305-1313

[15] Z. Yu, D. Zinger, A. Bose, An innovative optimal power allocation strategy for fuel cell, battery and supercapacitor hybrid electric vehicle, J. Power Sources 196 (2011) 2351-2359

[16] R. Mustata, V. Roda, A. Nueno, L. Valiño, A. Lozano, F. Barreras, J.L. Bernal, J. Carroquino, Small scale demonstration project for the production and use of hydrogen from renewable energy sources in the wine sector, Proceedings of the $21^{\text {st }}$ World Hydrogen Energy Conference, WHEC (2016) 383-384

[17] T. Ramsden, D. Steward, J. Zuboy, Analyzing the Levelized Cost of Centralized and Distributed Hydrogen Production Using the H2A Production Model, Version 2, Technical Report NREL/TP-560-46267, National Renewable Energy Laboratory, Golden, CO, USA, (2009)

[18] K. Nikiforow, H. Karimäki, T.M. Keränen, J. Ihonen, Optimization study of purge cycle in proton exchange membrane fuel cell system, J. Power Sources 238 (2013) 336-344

[19] A.J.L. Verhage, J.F. Coolegem, M.J.J. Mulder, M.H. Yildirim, F.A. de Bruijn, 30,000 h operation of a $70 \mathrm{~kW}$ stationary PEM fuel cell system using hydrogen from a chlorine factory, Int. J. Hydrogen Energy 38 (2013) 4714-4724

[20] T.M. Keranen, H. Katimaki, K. Nikoforow, S. Kukkonen, H. Uusalo, J. Viitakangas, J. Ihonen, A $50 \mathrm{~kW}$ PEMFC pilot plant operated with industry grade hydrogen-system designed and site integration, Fuel Cells, 14 (2014), 701-708 
[21] J-J. Hwang, Passive hydrogen recovery schemes using a vacuum ejector in a proton exchange membrane fuel cell system, J. Power Sources 247 (2014) 256-263

[22] P. Koski, L. C. Pérez, J. Ihonen, Comparing anode gas recirculation with hydrogen purge and bleed in a novel PEMFC laboratory test cell configuration, Fuel Cells 15 (2015) 494-504

[23] K. Nikiforow, P. Koski, J. Ihonen, Discrete ejector control solution design, characterization, and verification in a 5 kW PEMFC system, Int. J. Hydrogen Energy 42 (2017) 16760-16772

[24] H. Jiang, L. Xu, Ch. Fang, X. Zhao, Z. Hu, J. Li, M. Ouyang, Experimental study on dual recirculation of polymer electrolyte membrane fuel cell, Int. J. Hydrogen Energy 42 (2017) 18551-18559

[25] L. Dumercy, M.C. Péra, R. Glises, D. Hissel, S. Hamandi, F. Badin F, et al., PEFC stack operating in anodic dead end mode, Fuel Cells 4 (2004) 352-357

[26] J. Chen, J.B. Siegel, A.G. Stefanopoulou, J.R. Waldecker, Optimization of the purge cycle for dead-ended anode fuel cell operation, Int. J. Hydrogen Energy 38 (2013) 5092-5105

[27] A.P. Sasmito, M.I. Ali, T. Shamim, A factorial study to investigate the purging effect on the performance of a dead-end anode PEM fuel cell stack, Fuel Cells 15 (2015) 160-169

[28] Y. Yang, X. Zhang, L. Guo, H. Liu, Overall and local effects of operating conditions in PEM fuel cells with dead-ended anode, Int. J. Hydrogen Energy 42 (2017) 46904698

[29] F. Barreras, M. Maza, A. Lozano, S. Báscones, V. Roda, J.E. Barranco, M. Cerqueira, A. Vergés, Design and development of a multipurpose utility AWD electric vehicle with a hybrid powertrain based on PEM fuel cells and batteries, Int. J. Hydrogen Energy 37 (2012) 15367-15379

[30] R. Borup, J. Meyers, B.S. Pivovar, Y.S. Kim, R. Mukundan, N. Garland, et al., Scientific aspects of polymer electrolyte fuel cell durability and degradation, Chemical Review 107 (2007) 3904-3951

[31] M. Kim, Y-J. Sohn, W-Y. Lee, C-S. Kim, Fuzzy control based engine sizing optimization for a fuel cell/battery hybrid minibus, J Power Sources 178 (2008), 
706-710

[32] M. Ansarey, M.S. Panahi, H. Ziarati, M. Mahjoob, Optimal energy management in a dual-storage fuel-cell hybrid vehicle using multi-dimensional dynamic programming, J Power Sources 250 (2014) 359- 371

[33] T. Fletcher, R. Thring, M. Watkinson, An Energy Management Strategy to concurrently optimize fuel consumption \& PEM fuel cell lifetime in a hybrid vehicle, Int. J. Hydrogen Energy 46 (2016) 21503-21515

[34] A.M. Phillips, M. Jankovic, K.E. Bailey, Vehicle system controller design for a hybrid electric vehicle. Control Applications (2000) in: Proceedings of the 2000 IEEE International Conference

[35] S.F. Tie, C.W. Tan, A review of energy sources and energy management system in electric vehicles, Renewable and Sustainable Energy Review (2013) 82-102

[36] W.R. Baumgartner, P. Parz, S.D. Fraser, E. Wallnoefer, V. Hacker, Polarization study of a PEMFC with four reference electrodes at hydrogen starvation conditions, J. Power Sources 182 (2008) 413-421

[37] Y. Lee, B. Kim, Y. Kim, An experimental study on water transport through the membrane of a PEFC operating in the dead-end mode, Int J. Hydrogen Energy 34 (2009) 7768-7779

[38] J.B. Siegel, S.V. Bohac, A.G. Stefanopoulou, S. Yesilyurt, Nitrogen front evolution in purged polymer electrolyte membrane fuel cell with dead-ended anode. J Electrochem Soc., 157 (2010) B1081-B1093

[39] T. Matsuura, J. Chen, J.B. Siegel, A.G. Stefanopoulou, Degradation phenomena in PEM fuel cell with dead-ended anode, Int J. Hydrogen Energy 38 (2013) 11346-56 